\title{
KNOWLEDGE, ATTITUDE AND PRACTICE ON PHYSICAL AND PSYCHO- SEXUAL WELL BEING IN A COHORT OF POST MI PATENTS IN A SRI LANKAN TERTIARY CARE CARDIAC CENTER
}

H.G.W.A.P.L. Bandara ${ }^{1}$, U.I. Hewarathna ${ }^{1}$, T. Kogulan ${ }^{1}$, R.M.S.P. Karunarathne' ${ }^{1}$, N.W. Kodithuwakku' A. Jegavanthan ', A.W.D.T. Ambagaspitiya ', D.M.J.M.H. Ambagammana', R. Tennakoon',

S. R. Jayawickreme', S. N.B. Dolapihilla ${ }^{1}$, G. Weerakoon ${ }^{1}$

${ }^{1}$ Cardiology Unit, Teaching Hospital, Kandy, Sri Lanka

Correspondence: Dr. HGWAPL Bandara, e-mail: 1akshmanbandara@gmail.com

\begin{abstract}
Background

The major challenges in survivors following myocardial infarction (MI) are to prevent the subsequent coronary events for the achievement of a better quality of physical and psycho-sexual wellbeing. Issues pertaining to resumption of sexual activity, quitting smoking and psycho-social wellbeing are addressed as an integral part of the cardiac rehabilitation programme.
\end{abstract}

\section{Objectives}

To explore the knowledge, attitude and practice pertaining to physical and psycho-sexual wellbeing among post MI patients and to identify the lapses in current practice with regard to patient management with the aim of designing a locally relevant cardiac rehabilitation programme.

\section{Methods}

Across-sectional observational study was conducted at Cardiology unit, Teaching Hospital Kandy in 2015 recruiting a cohort of post MI patients who attend to Cardiology outpatient clinic. A pre-tested interviewer administered questionnaire and relevant medical records were used to obtain information.

\section{Results}

Though the majority were aware about the advantages of physical exercise following MI, most were unaware about the exact time of commencement and the self-adjustment of their exercise programme. The prevalence of anxiety and depression, especially the borderline cases were higher in post MI population than in the normal population independent of other clinical and demographic parameters. The participants had commenced sexual activity following the MI, however majority had reduced the frequency than before. Information on commencement of sexual activity was minimally conveyed and only a handful of patients discussed openly about their sexual activity with the health care providers. With regard to Health related quality of life (HRQoL) assessment, women had lower values than men and diabetic patients scored poorly than non-diabetics, especially in emotional wellbeing and endurance level. Majority of male patients were engaged in smoking. The majority had received help to quit smoking and succeeded in it, however, a significant proportion still continued to smoke even after the coronary event.

\section{Conclusion}

This study highlights the areas that need to be improved in the post MI care, especially with regard to sexual education, post MI graded exercise, improving quality of life, assistance to quit smoking and identifying the at risk patients for psychological diseases. 


\section{Introduction}

Coronary artery disease (CAD) is one of the major causes of mortality and morbidity in Sri Lanka. The reported prevalence of CAD in Sri Lankan adults is $9.3 \%{ }^{1}$. This includes a spectrum of diseases, varying from stable angina, unstable angina, myocardial infarction (MI) and sudden cardiac death. Out of these diseases, MI is a commonly discussed topic among the normal population. The major challenges in those who survive following myocardial infarction are to prevent the subsequent coronary events, to achieve a better quality of physical and mental wellbeing. In this background secondary prevention is a crucial aspect of the contemporary post MI care of a patient with CAD.

Cardiac rehabilitation or secondary prevention strategies are recognized as integral to the comprehensive post MI care of patients with CAD. It is also suggested as a valuable and effective (Class I) tool by the American Heart Association and the American College of Cardiology in the treatment of patients with $\mathrm{CAD}^{2}$.

Cardiac rehabilitation should be commenced as soon as possible following hospital admission and before discharge from the hospital $^{3}$. However, in Sri Lanka, the effectiveness of cardiac rehabilitation programs, which are currently in practice, were not evaluated up to now.

Therefore, this study was designed to explore the knowledge, attitude and practice with respect to post MI care among our patients. The study expands into different arms with special interest to the state of physical activity, psycho-sexual aspect and health related quality of life.

The resumption of physical activity following MI is highlighted in every aspect of cardiac rehabilitation and one of the major challenges is to overcome the patients' fear of commencing physical exercise. The exercise programme should be prescribed in a suitable mode, frequency, strength, and a duration, which should be tailored to the individuals' cardiovascular status as well as by considering the patients' attitudes ${ }^{4}$. Current recommendations indicate, all patients (regardless of their age) should be offered guidance of a cardiac rehabilitation programme with an exercise component ${ }^{3}$.

Cessation of smoking and commencement of exercise play pivotal roles in secondary prevention of CAD. However the patients motivation and management of failures of smoking cessation are minimally discussed in the local health setting. Following MI, some may experience psychological reactions (emotional imbalances) such as low mood, tearfulness, sleep disturbance, irritability, anxiety, acute awareness of minor somatic sensations and poor concentration ${ }^{3}$. Mounting evidence suggest that depression and anxiety have links to upsurge cardiac morbidity and mortality following major coronary event ${ }^{5}$. Therefore, early recognition and avoidance of risk factors for anxiety or depression can decrease the years of life lost or disability resulting from an acute MI. Sexual life plays an important role in physical and mental well-being of a person which needs to be finely adjusted following MI to achieve a better quality of life. This topic needs to be discussed with patients in a background of cardiac rehabilitation and aftercare ${ }^{3}$. Sexual activity is a parameter of health considerably influencing selfassessment of the quality of life.

Assessment of health related quality of life (HRQoL) in post MI patients is an important indicator of long term health status. This also provides information on future risks for deterioration of health status among these patients. Many studies show that, symptoms experienced are one of the most important risk factors for poor HRQoL and some of the subgroups appear to have very poor HRQoL in post MI period ${ }^{4}$. Cardiac rehabilitation should be conducted in a non-judgmental, respectful and culturally sensitive manner. Therefore, the above mentioned aspects were explored in this study aiming to formulate a better rehabilitation programme for post MI patients in local health setting. 


\section{Methodology Study design}

A cross-sectional observational study was conducted at Cardiology unit, Teaching Hospital Kandy in 2015 among a cohort of post MI patients.

\section{Setting and sample}

Post-MI patients with a history of a coronary event within 0.5 to 5 years were recruited from the cardiology outpatient clinics. Patients who were brought from prisons, those with diagnosed psychiatric illnesses and those who had difficulty in conversing due to aggravated medical conditions were excluded.

\section{Demographic and clinical characteristics}

A pre-tested interviewer administered questionnaire was used to obtain demographic characteristics including age, gender, marital status, educational level, and monthly income. Medical records were used to obtain information about the state of MI, co morbid medical conditions and follow-up data.

The level of depression and anxiety was assessed using a standard scale of Hospital Anxiety and Depression Scale (HADS). This questionnaire compromises 14 questions with 7 questions inquiring about depression and the other 7 inquiring about anxiety. Each question has 4 answers scoring from 0 to 3 . The total score for depression and anxiety were calculated separately.

\section{0-7-normal}

$8-10$ - borderline

$>11$ - abnormal

For evaluation of the HRQoL, the translated version of the Medical Outcomes Survey 36Item Short Form (SF-36) was used. The SF36 is made up of 36 items grouped into eight components: Physical Functioning, Role of Physical limitations, Bodily Pain, General Health, Vitality, Social Functioning, Role of
Emotional limitations and Mental Health. Each component has a score from 0 to 100 , in which 0 corresponds to the worst general health status and 100 corresponds to the best health status.

\section{Data analysis}

Descriptive statistics were conducted for demographic and clinical data. SPSS version 17.0 was used for data entry and analysis. A p value of $<0.05$ or $95 \%$ confidence limit was considered as significant.

\section{Ethical consideration}

The study protocol was approved by the Research and Ethical Review Committee, General Hospital (Teaching) Kandy. Informed written consent was obtained from each participant.

\section{Results}

\section{Demographic characteristics}

A total of 103 patients were assessed. Mean age of the sample was $58 \pm 9$ years. Age distribution of the study sample is shown in Figure 01. There were $81 \%$ males and 19\% females.

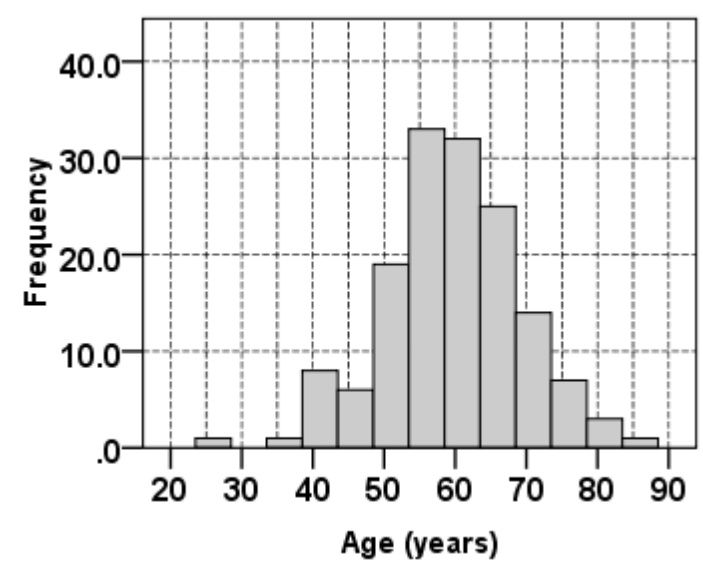

Figure 01.Age distribution of the study sample.

Observed variables of other vascular risk factors in the study sample are illustrated in Table 01 . 
Table 01. Prevalence of vascular risk factors among the study sample.

\begin{tabular}{|ll|}
\hline Comorbidities & Prevalence \\
\hline & \\
\hline Diabetes mellitus & $33 \%$ \\
\hline Hypertension & $38 \%$ \\
\hline Dyslipidemia & $56 \%$ \\
\hline
\end{tabular}

A description of socio-demographic characteristics of the study sample is given in Table 02.

Table 02. Socio-demographic data of the study sample.

\begin{tabular}{|lr|}
\hline Demographic factors & $\%$ \\
\hline Marital status & \\
Married & $95.3 \%$ \\
Unmarried & $2.7 \%$ \\
Widowed & $2.0 \%$ \\
Race & $77.3 \%$ \\
Sinhala & $16.7 \%$ \\
Muslim & $6.0 \%$ \\
Tamil & \\
Educational Status & $1.3 \%$ \\
Not had any primary education & $16.0 \%$ \\
Educated up to Grade 5 or less & $34.0 \%$ \\
Educated up to Grade $6-11$ & $31.3 \%$ \\
Qualified Ordinary level & $12.0 \%$ \\
Qualified Advanced level & $5.3 \%$ \\
Approached higher education & \\
levels & \\
Employment status & $39.3 \%$ \\
Employed & $36.7 \%$ \\
Un employed & $24.0 \%$ \\
Retired & \\
Monthly income(Sri Lankan & \\
rupees) & \\
<10000 & \\
10000-20000 & \\
20000-30000 & $16 \% .0 \%$ \\
>30000 & $10.7 \%$ \\
\hline \multicolumn{2}{l}{} \\
\hline
\end{tabular}

Physicalactivity (Exercise commencement) among the post MI Patients

A majority $(76 \%)$ had the impression that they can engage in exercise following MI, but $37 \%$ were unaware about the time of commencement, while only $42 \%$ had started exercise after one month following hospital discharge. Awareness of the advantages of post MI exercise was observed in $78 \%$. However $85 \%$ were unaware about adjusting their exercise programme by themselves (Table 03).

Table 03. The distribution of the different attitudes in perception of post MI exercise.

\begin{tabular}{|lr|}
\hline $\begin{array}{l}\text { Variables of the perception on } \\
\text { post MI exercise }\end{array}$ & $\begin{array}{r}\text { Prevel } \\
\text { ance }\end{array}$ \\
\hline $\begin{array}{l}\text { Positive impression on post MI } \\
\text { exercise }\end{array}$ & $76 \%$ \\
\hline $\begin{array}{l}\text { Awareness about the time of } \\
\text { starting exercise in post MI } \\
\text { period }\end{array}$ \\
\hline \multicolumn{2}{|c|}{ Just after discharge } \\
\hline \multicolumn{2}{|c|}{ During $1^{\text {st }}$ week } \\
\hline \multicolumn{2}{|c|}{ After $1^{\text {st }}$ week } \\
\hline \multicolumn{2}{|c|}{ After one month } \\
\hline \multicolumn{2}{|c|}{$\begin{array}{l}\text { Not aware about } \\
\text { the time of } \\
\text { commencement }\end{array}$} \\
\hline \multicolumn{2}{|c|}{$\begin{array}{l}\text { Attitude "no need } \\
\text { of exercise" }\end{array}$} \\
\hline $\begin{array}{l}\text { Awareness on positive benefits of } \\
\text { exercise }\end{array}$ \\
\hline $\begin{array}{l}\text { Awareness over the self- } \\
\text { adjustment of their exercise } \\
\text { programme }\end{array}$ \\
\hline
\end{tabular}

Evaluation of anxiety and depression in post MI period

The majority of participants (79\%) had no depression. There were only $5 \%$ with depression while $16 \%$ had borderline depression Figure (02). Depression or borderline depression was not statistically associated with gender $(\mathrm{p}=0.99)$. 


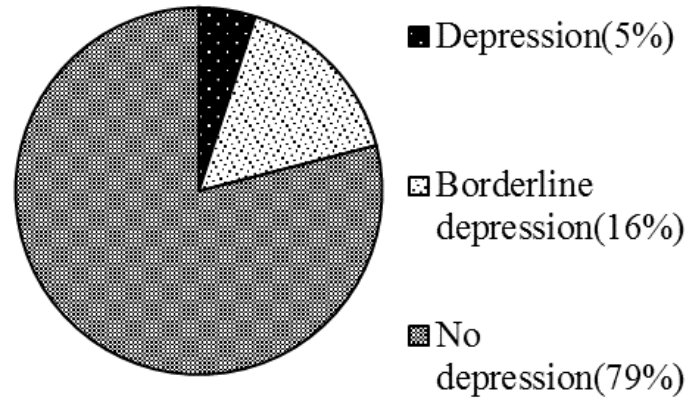

Figure 02. The distribution of depression among the study sample.

In the study sample the majority (84\%) had no anxiety. However, $2 \%$ had anxiety and $14 \%$ had borderline anxiety (Figure 03 ) and prevalence of anxiety or borderline anxiety did not have any gender difference $(p=0.397)$. Prevalence of depression was not associated with marital state $(p=0.9)$, monthly income below 20000(LKR) $(p=0.653)$ or educational level less than ordinary level $(\mathrm{p}=0.599)$.

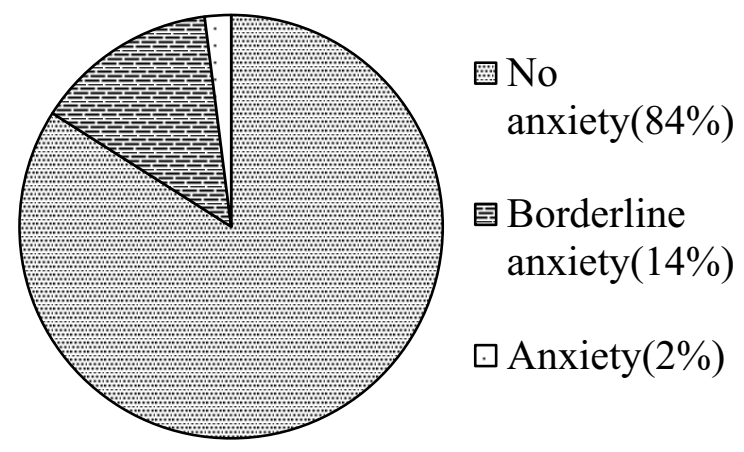

Figure 03. The distribution of anxiety among the study sample

\section{Mal-adjustments of sexual life among the study group}

Majority (66\%) had sexual activity within 12 months prior to the major cardiac event. However only $53 \%$ had sexual activity since having the MI and out of them 53\% had less frequency, $14 \%$ had the same frequency and $1 \%$ had increased frequency of engaging in sexual activity while $32 \%$ refused to answer.
Observed variation of the frequency of sexual intercourse among the study group is illustrated in Table 04.

Table 04. Distribution of sexual maladjustment in post MI study sample.

\begin{tabular}{|c|c|}
\hline \multicolumn{2}{|l|}{$\begin{array}{l}\text { Variable of mal-adjustment of } \\
\text { sexual life }\end{array}$} \\
\hline $\begin{array}{l}\text { Patients who were engaged in } \\
\text { sexual activity preceding } 12 \\
\text { months of MI }\end{array}$ & $66 \%$ \\
\hline $\begin{array}{l}\text { Portion who had sexual activity } \\
\text { following MI }\end{array}$ & $56 \%$ \\
\hline \multicolumn{2}{|l|}{$\begin{array}{l}\text { Distribution of sexual intercourse } \\
\text { frequency }\end{array}$} \\
\hline $\begin{array}{ll}\text { Increased } \\
\text { frequency }\end{array}$ & $1 \%$ \\
\hline Same frequency & $14 \%$ \\
\hline Less frequency & $53 \%$ \\
\hline $\begin{array}{l}\text { Refused to } \\
\text { answer }\end{array}$ & $32 \%$ \\
\hline
\end{tabular}

Only $16 \%$ received instructions on when to resume sexual activity following MI and only $7 \%$ had discussed about sexual activity with their physician, while no females were included in this group.

\section{Smoking status in post MI period}

Of the male patients, $62 \%$ engaged in smoking during their lifetime. Mean duration of cigarettes smoking was $20 \pm 12$ years with the mean number of cigarettes per day being $11 \pm 10$. None of the females were engaged in active smoking. Majority (96\%) of subjects appreciated that smoking was harmful. Out of the patients who continued smoking until their last coronary event, $93 \%$ tried to quit the habit following MI and $86 \%$ received help from the medical staff on that. However, only $82 \%$ were able to succeed while $18 \%$ continued to smoke. 


\section{Health-related quality of life}

Health related quality of life (HRQoL) was assessed using Short Survey (SF-36) questionnaire. Responses to each question were scored and summed according to a standard scoring protocol. The score ranged from $0-100$, where 0 denoted poor HRQoL and 100 denoted a better HRQoL. The summations of the scores belonging to each sub category of HRQoLis shown in Table 05.

Table 05. Distribution of different sub categories of HRQoL among the study sample.

\begin{tabular}{|ll|}
\hline Category & $\begin{array}{l}\text { Mean } \pm \\
\text { SD }\end{array}$ \\
\hline & \\
\hline Physical functioning & $62.7 \pm 28$ \\
\hline $\begin{array}{l}\text { Role of physical limitation due } \\
\text { to health }\end{array}$ & $42.0 \pm 40$ \\
\hline Role of emotional limitations & $63.3 \pm 43$ \\
\hline Energy or fatigue & $63.9 \pm 23$ \\
\hline Emotional wellbeing & $79.1 \pm 19$ \\
\hline Social functioning & $77.3 \pm 26$ \\
\hline Pain & $71.6 \pm 26$ \\
\hline General health & $56.7 \pm 18$ \\
\hline Health change & $55.6 \pm 26$ \\
\hline
\end{tabular}

Among the post MI patients, the HRQoL with regard to social functioning (77.3 \pm 26$)$, energy/fatigue (63.9 \pm 23$)$, and emotional well-being $(80 \pm 16)$ are relatively high, reflecting better HRQoL. Males scored higher than female in all categories (Table 06), but statistically significant association was noted only for physical functioning category $(\mathrm{p}=0.009)$.
Table 06. Variation of each sub categories of HRQoL among gender.

\begin{tabular}{|c|c|c|}
\hline Cat & \multicolumn{2}{|c|}{ Mean \pm SD } \\
\hline & Male & Female \\
\hline $\begin{array}{l}\text { Physical functioning } \\
(p=0.868)\end{array}$ & $65.8 \pm 27$ & $49.5 \pm 27$ \\
\hline $\begin{array}{l}\text { Role of physical } \\
\text { limitation due to } \\
\text { health }(p=0.876)\end{array}$ & $42.6 \pm 40$ & $39.2 \pm 38$ \\
\hline $\begin{array}{l}\text { Role of emotional } \\
\text { limitations }(p=0.786)\end{array}$ & $64.5 \pm 43$ & $58.3 \pm 46$ \\
\hline $\begin{array}{l}\text { Energy or fatigue } \\
(p=0.512)\end{array}$ & $65.0 \pm 17$ & $59.2 \pm 29$ \\
\hline $\begin{array}{l}\text { Emotional wellbeing } \\
(p=0.928)\end{array}$ & $80.2 \pm 17$ & $74.0 \pm 25$ \\
\hline $\begin{array}{l}\text { Social functioning } \\
(p=0.465)\end{array}$ & $79.2 \pm 24$ & $69.2 \pm 32$ \\
\hline Pain $(p=0.886)$ & $72.4 \pm 26$ & $68.0 \pm 28$ \\
\hline $\begin{array}{l}\text { General health } \\
(p=0.736)\end{array}$ & $57.3 \pm 18$ & $54.3 \pm 19$ \\
\hline $\begin{array}{l}\text { Health change } \\
(p=0.442)\end{array}$ & $56.3 \pm 26$ & $52.7 \pm 29$ \\
\hline
\end{tabular}

Patients who had diabetes had lower scores than non-diabetic group in all categories, with significantly lower values in energy/fatigue $(p=0.012)$ and emotional wellbeing $(\mathrm{p}=0.028)$ categories (Table 07$)$.

Table 07. The variation of HRQoL among diabetics and non-diabetics

\begin{tabular}{|lll|}
\hline Category & \multicolumn{2}{c|}{ Mean \pm SDD } \\
\hline & & $\begin{array}{l}\text { Non } \\
\text { diabetic }\end{array}$ \\
\hline $\begin{array}{l}\text { Physical functioning } \\
\text { (p=0.368) }\end{array}$ & $57.5 \pm 28$ & $65.5 \pm 27$ \\
\hline $\begin{array}{l}\text { Role of physical } \\
\text { limitation due to } \\
\text { health (p=0.176) }\end{array}$ & $41 . \pm 40$ & $42.5 \pm 40$ \\
\hline $\begin{array}{l}\text { Role of emotional } \\
\text { limitations (p=0.286) }\end{array}$ & $53.3 \pm 43$ & $68.3 \pm 42$ \\
\hline $\begin{array}{l}\text { Energy or fatigue } \\
\text { (p=0.012) }\end{array}$ & $58.6 \pm 23$ & $66.6 \pm 22$ \\
\hline $\begin{array}{l}\text { Emotional wellbeing } \\
\text { (p=0.028) }\end{array}$ & $77.3 \pm 18$ & $80.0 \pm 19$ \\
\hline $\begin{array}{l}\text { Social functioning } \\
\text { (p=0.065) }\end{array}$ & $77.7 \pm 24$ & $77.2 \pm 27$ \\
\hline Pain (p=0.086) & $69.1 \pm 25$ & $72.8 \pm 27$ \\
\hline $\begin{array}{l}\text { General health } \\
\text { (p=0.236) }\end{array}$ & $55.8 \pm 18$ & $57.3 \pm 19$ \\
\hline $\begin{array}{l}\text { Health change } \\
\text { (p=0.342) }\end{array}$ & $52.5 \pm 24$ & $57.3 \pm 27$ \\
\hline
\end{tabular}


Female and diabetic post MI patients had relatively poor HRQoL in all categories, though the differences were not statistically significant.

\section{Discussion}

Physical and psycho-sexual well-being is a sensitive and a critical aspect of post MI care with special reference to secondary preventive strategies. This study highlighted some key status quo of the post MI care in the local health community.

\section{Commencement of exercise}

Though the majority of patients had the impression that they can engage in exercise during the post MI period, many of them were unaware about the commencement and the adjustment of their exercise programme. Due to the deficiency of knowledge in primary concepts, most of them are likely to have sub-optimal exposure to physical exercise following MI. Some may still have the fear of exercise after the acute coronary event and the study highlights the importance of this fact in the post MI care delivered in local community. Even in developed countries, it has been identified that a significant delay on the commencement of exercise programmes in Cardiac Rehabilitation (CR) setting exists and this may have shown that delayed CR significantly impacts fitness outcomes. For every 1-day increase in CR wait time, patients were $1 \%$ less likely to improve across all fitness-related measures ${ }^{6}$.This highlights the necessity to implement a graded exercise programme with health education at the community level to achieve therapeutic goals in post MI physical rehabilitation.

\section{Evaluation of anxiety and depression}

The prevalence of anxiety and depression is higher in post MI population than the normal population. It has been shown in studies that, depression in hospital after $\mathrm{MI}$ is a significant predictor of 1-year cardiac mortality for women as well as for men, and its impact is largely independent of other
post-MI risk factors ${ }^{4}$. This study indicates that, there is a considerable prevalence of borderline depression and anxiety among our post MI population, which needs special attention. This category of patients is an important group, since they may be benefited from early non - pharmacological interventions by preventing them falling into either depression or anxiety. Addressing these issues may improve the patients' quality of life and possibly the prognosis. The findings encourage continuous evaluation of post MI patients in a regular manner to identify these risk categories in early stages of the disease. In addition to the above patients should be promptly referred to a community psychiatrist for evaluation and initiation of early psychotherapy. At the same time HADS questionnaire is also be considered as a simple and practicable tool in assessing our post MI patients in the outpatient setting.

\section{Sexual life adjustment}

Delivery of information on post MI sexual care is poor and open discussion of the issue with the physician is lacking in the study population. In an Asian country like Sri Lanka this matter is mostly culturally bound and usually an unspoken aspect of post MI care. Sexual matters especially in females will not be openly discussed in the general clinics and this may have a huge impact on their quality of life. However in western literature, some studies have shown that partnered women commonly resume sexual activity soon after an MI with fear but without direct counseling from their physicians 7 . However in our study none of the females had an active discussion with the physician on this matter. Since such sensitive information is not being discussed with our patients, especially in females with CAD such an active discussion should be initiated from the side of the physician.

This study emphasizes the requirement to implement a post MI sexual education programme in a standard manner to improve the safety and quality of life in our post MI patients, especially females. 


\section{Smoking status}

Although active motivation on cessation of smoking is undertaken considerable numbers of patients still continue to smoke. This is an important aspect that should be discussed in the secondary prevention of CAD. One of the reasons for this failure may be the non-popularity of other modalities of smoking cessation strategies (i.e. nicotine replacement, bupropion, e-cigarette etc.) among primary care physicians in the local health set-up. Evidence suggest that CR programme can significantly cut-dawn the amount of smokers in the post MI period ${ }^{8}$. Identifying patients with difficulties in stopping smoking and referring to a specialist for proper management of smoking cessation may be necessary.

\section{Health-related quality of life}

Females as well as diabetic post MI patients have relatively poor HRQoL in all categories in the study population. It has been accepted that females generally have poor HRQoL compared to male population and relatively similar findings were observed in the studied local community. Additionally South East Asian population has cultural female isolations which further worsens the poor HRQoLin the post MI period.

Diabetic patients have generally multiple complications due to the disease process which restricts the patients physical functioning as well as psycho-social wellbeing when compared to non-diabetic patients $^{10}$. Therefore, these groups need special attention with respect to improvements of their HRQoL, through a well-designed cardiac rehabilitation programme.

\section{Conclusion}

This study highlights the unattended and under recognized areas in delivering post MI care in a local setting. These findings emphasize the need of implementing a high quality cardiac rehabilitation programme aiming successful secondary preventive goals and upgrading the patients quality of life. Sexual education has to be delivered to every patient in a setting where issues could be confidentially addressed. Patients with borderline depression and anxiety have to be picked up early to prevent future adverse outcomes. Women in particular those who have lower HRQoL needs early specialized attention. Smoking cessation programmes which are part of cardiac rehabilitation needs to be expanded to encourage and guide patients to quit smoking as well as to maintain abstinence. Overcoming these highlighted lapses in post MI care can be utilized to achieve a well planned highly effective and patient centered cardiac rehabilitation programme.

\section{Limitations}

It might not be possible to generalize the findings in the study to the entire Sri Lankan post MI population since this is a single center experience. However, the center receives large number of patients for cardiac care from most parts of Sri Lanka. We have used the translated version of HADS and HRQoL SF 36 questionnaire though not the validated version. Since some of the information gathered is very sensitive and confidential, some may not have revealed the true picture in some instances such as sexual activity. This is one of the major limitations that we encountered in our cultural setting.

\section{Acknowledgements}

We express sincere gratitude to our patients at the Cardiology Unit Kandy and the staff of the Cardiology unit, for their contribution towards the success of this study.

\section{References}

1. Katulanda P, Liyanage I K, Caldera R, Constantine G R, Sheriff R, Mathews D. Prevalence of ischaemic heart disease and its risk factors in Sri Lanka. Ceylon Medical Journal. 2010; 55 (Supplement 1): 53. 
2. Balady G J, Williams M A, Ades P A, Bittner V, Comoss P, Foody J M, et al Core Components of Cardiac Rehabilitation/Secondary Prevention Programs: 2007 Update: A Scientific Statement From the American Heart Association, Exercise, Cardiac Rehabilitation, and Prevention Committee, the Council on Clinical Cardiology; the Councils on Cardiovascular Nursing, Epidemiology and Prevention, and Nutrition, Physical Activity, and Metabolism; and the American. Association of Cardiovascular and Pulmonary Rehabilitation. Circulation 2007;115:2675-2682.

3. Myocardial infarction: cardiac rehabilitation and prevention of further cardiovascular disease Clinical guideline Published 13 November 2013 Available at https://www.nice.org.uk/guidance/cg172. [Accessed November 2016]

4. Frasure-Smith N, Lespérance F, Juneau M, Talajic M, Bourassa MG. Gender, depression, and one-year prognosis after myocardial infarction. Psychosom Med. 1999 Jan-Feb;61(1):26-37.

5. Parashar S, Rumsfeld JS, Reid KJ, Buchanan D, Dawood N, Khizer S, Lichtman J, Vaccarino V; PREMIER Registry Investigators.. Impact of depression on sex differences in outcome after myocardial infarction. Circ Cardiovasc Qual Outcomes. 2009 Jan;2(1) : 33 - 40. Doi:10.1161/ CIRCOUTCOMES.108.818500.
6. Fell J, Dale V, Doherty P. Does the timing of cardiac rehabilitation impact fitness outcomes? An observational analysis. Open Heart. 2016 Feb 8;3(1):e000369. Doi:10.1136/openhrt2015-000369. eCollection 2016.

7. Abramsohn EM, Decker C, Garavalia B, Garavalia L, Gosch K, Krumholz HM, Spertus JA, Lindau ST. "I'm not just a heart, I'm a whole person here": a qualitative study to improve sexual outcomes in women with myocardial infarction. J Am Heart Assoc. 2013 Jul 2 4;2 (4): e000199.

Doi:10.1161/JAHA.113.000199.

8. Goldstein MG, Niaura R. Methods to enhance smoking cessation after myocardial infarction. Med Clin North A m . $2000 \mathrm{~J}$ a n ; 84 (1): 63 - 80. Doi:10.1016/S0025-7125(05)70207-8

9. Gijsberts CM, Agostoni P, Hoefer IE, Asselbergs FW, Pasterkamp G, Nathoe H, Appelman YE, de Kleijn DP, den Ruijter HM. Gender differences in health-related quality of life in patients undergoing coronary angiography. Open Heart. 2015 Aug 27;2(1):e000231. Doi:10.1136/openhrt2014-000231. eCollection 2015

10. Jain V, Shivkumar S, Gupta O. Healthrelated quality of life (hr-qol) in patients with type 2 diabetes mellitus. N Am J Med Sci. 2014 Feb;6(2):96101. Doi:10.4103/1947-2714.127752. 